\title{
Wind Energy Based Packet Energy System
}

\author{
Md Shakhawat Hossain ${ }^{* 1}$, M. Tariq Iqbal ${ }^{2}$ \\ Faculty of Engineering and Applied Science, Memorial University of Newfoundland \\ St. John's, NL, Canada \\ ${ }^{* 1}$ msh358@mun.ca; 2tariq @mun.ca
}

Received 18 March 2014; Accepted 16 April 2014; Published 3 July 2014

(C) 2014 Science and Engineering Publishing Company

\begin{abstract}
This paper proposes a wind turbine and battery storage based packet energy system. The proposed energy packet network can be used to make renewable energy sources more practical and supply energy on demand. The flow of energy in the energy packet network is controlled by a Smart Energy Dispatching Centres (SEDC). SEDCs receive the energy requests from the customers and it tries to optimize the energy flows by making the best use of renewable energy resources, existing price and policies. The proposed energy system can take energy flow instructions from a SEDC. In the present analysis a small wind energy system with battery storage has been simulated in Matlab/Simulink. The system has been modelled using low order transfer functions. Random switching has been done to get energy packets from the model. A prototype of the battery based energy storage system has been designed and implemented. Lab tests and simulation results indicates that the designed packet energy network system is able to provide energy packet as required by the grid. Additionally the output power from a very large energy packet network is also found to be stable with the existence of large load fluctuation.
\end{abstract}

\section{Keywords}

Smart Grid; Smart Meter; Packet Energy; Battery Storage; Wind Energy

\section{Introduction}

The Smart Grid is considered as the next generation energy grid. Two-way flows of electricity and information makes it a widely distributed and automated energy delivery network. The smart infrastructure system, the smart management system, and the smart protection system are the major three parts of smart grid [1]. Renewable sources of energy, such as wind and solar, have gained attention over the last few decades. Presently, these are the key components to build a clean electric grid. The renewable energy sources such as solar photovoltaics, wind turbines, wave power, small hydroelectric units and marine current power all are typically unpredictable and sometimes aperiodic. Renewable energy sources are unpredictable elements on the supply side. Demand side of the energy market is also unpredictable. Energy storage systems such as the battery storage can offer new opportunities to improve the interaction between varying supply and demand.

Smart grid is designed with extensive interconnections. Reliability is the main concern of these interconnections. Interconnection also increases the risk of failure. Any imbalance can spread to the wide area. If large proportions of renewable energy generation need to be connected to the grid without the risk of wide area failures, a new electric power grid needs to develop, and various approaches are considered in [2]-[3]. A smart grid can also be designed where demand-side management of power usage is put into effect through a parallel information network [4]. The problems of power flow cannot be solved by only demand-side management. Impedance is relatively static in the traditional grid but it is dynamic in a distributed generation grid. Integration of large proportion of renewable energy sources is also hard because it is difficult to maintain synchronization over a wide area.

In [5] a new type of power system is proposed. Here a wide-area synchronized power system is subdivided into smaller or medium sized cells. And these cells are connected through asynchronous coordination control. By separating the power grid into cells, the fluctuations of renewable power can be managed within the cell. The fluctuations of one cell cannot affect other cells because each cell is separated by ac/dc/ac conversion. In this way a digital grid can accept high penetrations of renewable energy. It can also help to prevent wide area blackout. If fault occurs in a line, power can flow through other paths because a number of such paths are available among cells.

In [6] plug-in vehicle charging has been proposed 
using charge packets which are analogus to discrete data packets used in communication system. Here packetized charging breaks the required charge time into many small intervals or packets. A charge management coordinator device at the distribution substation determines whether additional load on the system can be served. If charging is not possible with existing resources, the PEV will resubmit a request after a certain time. If charging is possible, the PEV will charge for the duration of the packet. PEV will submit new requests for subsequent packets until the battery is fully charged. Here it is also recommended that $5 \mathrm{~s}$ request interval and $5 \mathrm{~s}$ packet in length is superior in terms of both total cost and equal access.

The objective of this research is to design a small wind energy based packet energy system. The system is based on wind turbines and battery storage. Wind turbine will charge the batteries depending upon the wind availability. Smart energy dispatch center sends request to energy storage system through advanced metering infrastructure to provide energy packet of a fixed duration. The duration of energy packet will be decided by the dispatch center depending on the energy demand from customers, load forecast and energy production. Each packet magnitude will be the name plate rating of the grid-tie inverter. In other words grid-tied inverter on/off time and duration will be decided by the SEDC. A SEDC will always have an updated status of battery-inverter system that could supply energy packets. Proposed system is modelled and simulated in Matlab/Simulink. Simulation indicates that the proposed Energy Packet Network (EPN) is able to provide power as needed with the presence of renewable energy sources. The EPN can store energy originating from renewable energy sources. And the stored energy can complement the traditional sources of energy in pulses form when demand is high. A prototype of the battery based energy storage system has been designed and implemented in this research to demonstrate the system and its ability to provide energy packets without any issue.

Rest of the paper is organized as follows. The concept of energy packet network has been discussed in the next section. Modelling and simulation output has been shown in successive sections. The output of the experimental setup is shown in the experiment section.

\section{Energy Packet Network}

Energy packet network offers smart management of energy flow. Here energy flows like a packet in the internet rather than the continuous instantaneous flow of current towards points of energy consumption. Energy packet can be described as a pulse of power which lasts for a certain time. So the unit of the energy packet is $\mathrm{kWh}$. The duration of the energy packet is determined by the grid according to the requirement. The flow of energy in energy packet network is controlled by a Smart Energy Dispatching Centres (SEDCs) which is basically a computer control center. SEDCs receive the current state of all energy storage systems from the consumers and estimate energy requirement based on forecast. It tries to optimise the energy flows by making the best use of available renewable energy sources and existing pricing policies. From customer point of view, essentially a SEDC sends random demand pulses (turn on duration and time) to a renewable energy system with storage and collects current status of battery charge. A SEDCS use data communication networks to receive and send information and make optimal dispatching decisions. It will also have the updated status of every components connected to it.

An energy packet network can serve different purposes [7]:

- Provide real-time information about the requests on the one hand, and the sources of energy on the other.

- Schedule the flow of current to and from electricity storage units depending on the availability and demand.

- Real-time scheduling of energy demand so as to meet certain desirable objectives, e.g. scheduling electric heating in a large building.

In [8], authors proposed two in-home power distribution systems. Information is added to the electric power distribution and electricity is distributed according to the supplied information. A switching circuit system based on alternating current (AC) power distribution and a switching circuit based on direct current (DC) power dispatching system via power packets are proposed. But it requires high power switching devices.

An Internet-based energy provisioning concept has been proposed in [9]. Customers can order and request future power demands through a system called Online Purchase Electricity Now (OPEN). It will encourage customers to order the electricity they need and consume or store locally exactly what they ordered. 


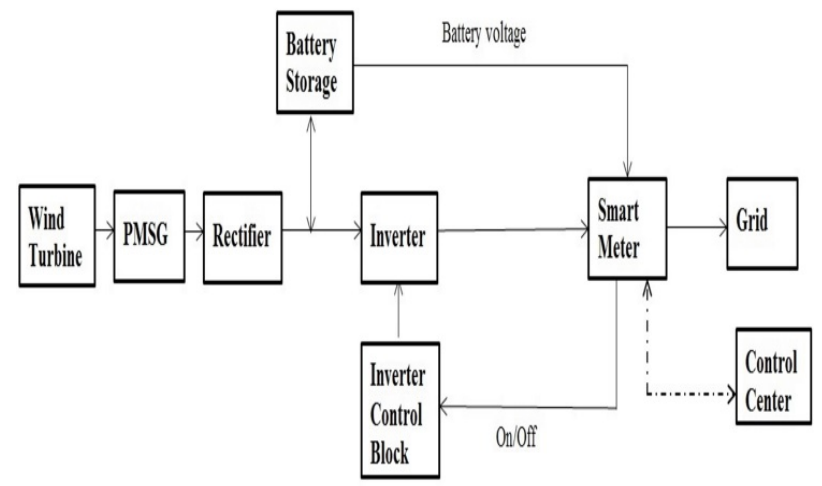

FIG. 1 SMALL WIND TURBINE WITH ENERGY STORAGE

The paper indicates that reliability of the electric grid can be improved with this kind of virtual energy provisioning system. System concepts and implementation strategies are also discussed in the paper. Several methods have been proposed to represent the demand orders for the customers [9].

\section{Average Demand Orders}

In this method, customers can order the average electricity demand that will be needed in hourly, daily, weekly, or monthly basis based on the historical consumption. Let $d(t)$ be the demand order in unit $k W h$ from customer $i$ at time $t$, then the total required generation, $\mathrm{g}(\mathrm{t})$, is

$$
g(t)=\sum_{i=1}^{n} d_{i}(t)
$$

where $\mathrm{n}$ is the number of customers and $\mathrm{t}$ represents a specific hour, day, week, or month.

\section{Lower and Upper Bounds Demand Orders}

In this method customers can also order the minimum and maximum energies that will be consumed in the future. It will give customers more flexibility to estimate their future energy consumptions. Let $d_{L}$ and $\mathrm{du}$ be the lower and upper demands from customer $i$, respectively, then the lower and upper generations is estimated by

$$
\begin{gathered}
g_{L}(t)=\sum_{i=1}^{n} d_{L i}(t) \\
g_{U}(t)=\sum_{i=1}^{n} d_{U i}(t)
\end{gathered}
$$

With this the supplier can make plan for the worst or the best scenarios of the future energy demand. If maximum energy demand of all customers is considered, it will be worst scenario which rarely occurs in reality.

\section{Demand Orders with Power and Time Duration}

In this method customers can order in terms of electric power plus the time duration.
Smart energy dispatching center can control the energy flow after getting the customer's order. For sources such control is effectively random requests of energy packets.

\section{Simulation of a Wind Energy System with Storage in Matlab/Simulink}

Fig. 1 shows the block diagram of a grid connected small wind energy system with battery storage. This system has been modelled in the Matlab/Simulink without the PID controller to get open loop response of the system. A $7.5 \mathrm{~kW}$ wind turbine is coupled with a 24 pole $300 \mathrm{rpm}$ permanent magnet synchronous generator (PMSG). The base wind speed and pitch angle is set to $12 \mathrm{~m} / \mathrm{s}$ and 0 degree respectively. Here $6 \mathrm{~V}, 305 \mathrm{Ah}$ batteries are used. Two strings of batteries are used in total. Each string has 8 batteries to make $48 \mathrm{~V}$ DC bus voltage. For AC to DC conversion uncontrolled rectifier has been used. The output of the rectifier is connected to the battery storage through a LC filter. Depending on the wind speed, battery bank will be charged from the wind turbine.

Battery and the output of the rectifier is connected to an inverter for DC to AC conversion. The output of the inverter is connected to the grid through three phase LC filter and transformer. The inverter will be controlled with a PID controller and PWM generator. A PID controller will be used to control the inverter switching. The output of the PID controller is connected to the inverter through the PWM generator. The whole system has been implemented in Matlab/Simulink without PID controller. The full system has been converted into simple first order transfer function as the full system simulation takes a long time in Matlab to complete. The transfer function model of the system was obtained using the step response of the full system model.

In next section the open loop system has been used to design an energy packet network.

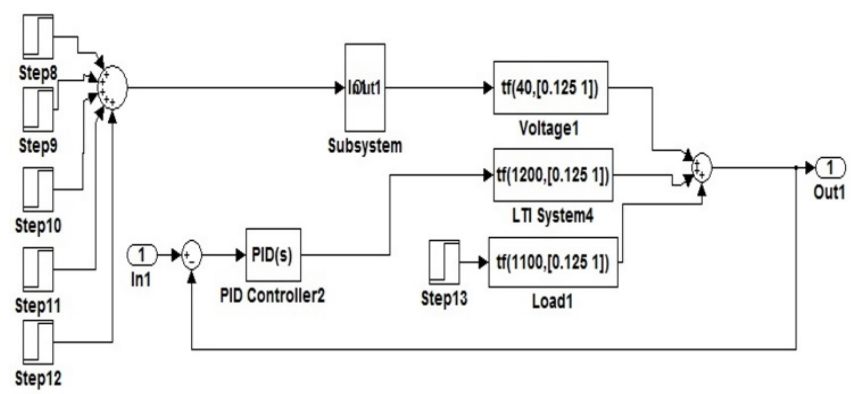

FIG. 2 TRANSFER FUNCTION MODEL OF THE WIND ENERGY SYSTEM 


\section{Modelling of Packet Energy System}

In this section the transfer function of the above described wind energy system with battery storage has been determined to design a packet energy network. The whole system has been divided into two parts to calculate the transfer function.

The first part consists of wind turbine, PMSG, rectifier and battery. For the first part the response of the battery voltage is calculated for different wind speeds such as 7, 8, 9, 10, $11 \mathrm{~m} / \mathrm{s}$. From the output response the transfer function of current going to the battery is found as equation (4).

$$
\begin{aligned}
\frac{I_{b}(s)}{W_{s}(s)} & =\frac{8}{0.72 s+1} \\
\frac{P_{\text {out }}(s)}{V_{b}(s)} & =\frac{40}{0.125 s+1}
\end{aligned}
$$

Here $I_{b}$ is battery charging current $(A)$ and $W_{s}$ is wind speed. From the output response steady state gain and time constant has been calculated. Steady state gain is found 8 and time constant is $0.72 \mathrm{~s}$. It is then multiplied by the internal resistance of the battery to calculate the response of the battery voltage for different wind speeds. The output of the first part has been used as the input to a voltage controlled voltage source. And that voltage controlled voltage source is connected to the inverter. Another transfer function has been determined to include the effect of voltage change of the voltage sourced inverter on the output power which is shown in equation (5) with the time constant $0.125 \mathrm{~s}$ and steady state gain of 40 . Here $P_{\text {out }}$ is the output power of the inverter $(\mathrm{W})$ and $\mathrm{V}_{\mathrm{b}}$ is battery voltage.

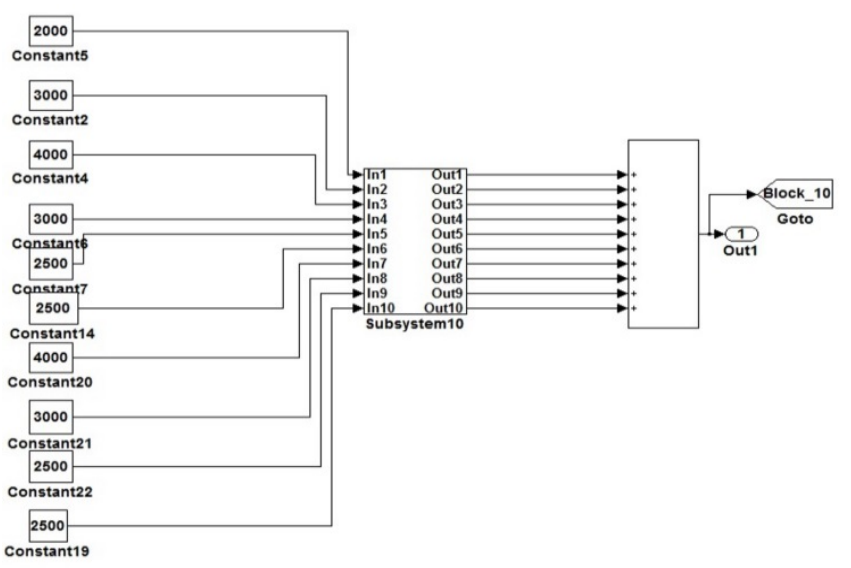

FIG. 310 BLOCKS WITH DIFFERENT REFERENCE POWER

The second part of the system model consists of voltage sourced inverter and rest of the components of fig. 1. Two more transfer functions have been determined for this model. One is to get the effect of the load change and another one is to get the effect of modulation index change on the output power of the inverter. Step input has been provided to the circuit breaker in Matlab/Simulink to increase the load which helps to find the effect of load change in output power of the inverter. The transfer function due to the load change is shown in equation (6). Here Cload stands for change of load. And step input has been provided to the PWM generator to find the effect of different modulation index on the output power of the inverter. From the output response steady state gain and time constant has been calculated. And the transfer function due to the modulation index change is shown in equation (7). Here СРwм stands for the change in PWM change.

$$
\begin{aligned}
& \frac{P_{\text {out }}(s)}{C_{\text {load }}(s)}=\frac{1100}{0.125 s+1} \\
& \frac{P_{\text {out }}(s)}{C_{P W M}(s)}=\frac{1200}{0.125 s+1}
\end{aligned}
$$

Fig. 2 shows the transfer function model of the wind energy system with storage of fig. 1 .

After getting the open loop transfer function of the system in fig. 1, a PID controller is used to get constant active power from the wind energy system which is determined by the reference power. Controller gains have been adjusted using the automatic tuning method in Matlab/Simulink.

Energy dispatch center selects storage system depending on the energy demand, energy production and status of the battery storage. This is random selection from the customer point view. Random switching is done to produce power packet from the designed packet energy system to implement this idea. Fig. 2 is considered as 1 block in the packet energy network. The first plot of Figure. 4 shows the output power of one block where reference power is set to 2 $\mathrm{kW}$. The duration of each packet depends on the command from the smart energy dispatching center. Smart energy dispatching center will make this decision depending on the request from the customers and availability of the power in the power stations.

Fig. 3 shows a bit more complicated system where 10 blocks have been added with different reference power. Here it is assumed that each cell has different amount of power generation. Second plot of Fig. 4 shows the total output power from the ten blocks where all blocks generate power randomly in energy packets form. 

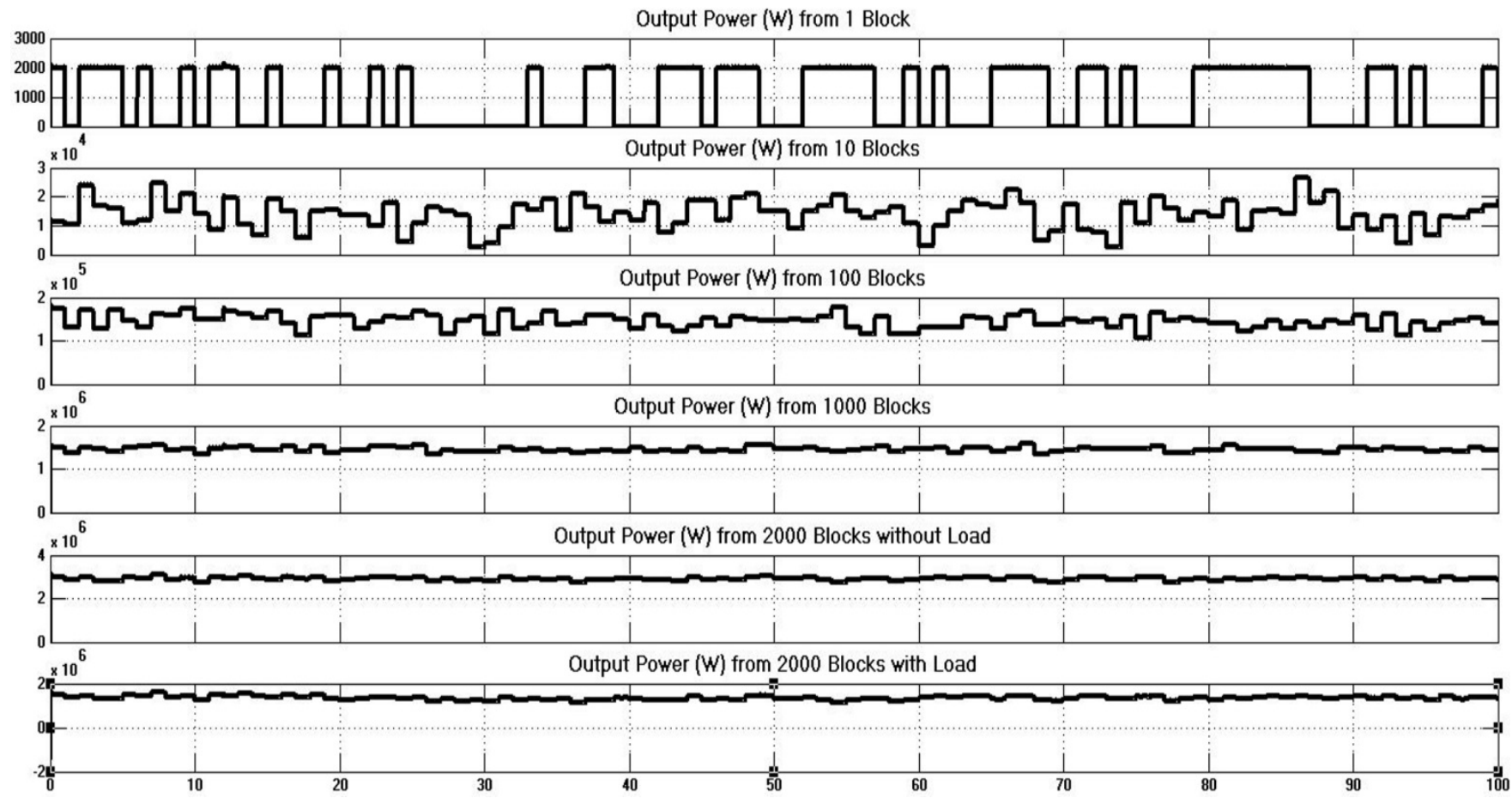

FIG. 4 OUTPUT POWER FROM DIFFERENT NUMBER OF BLOCKS

A large number of this kind of blocks can be considered to form a grid that is a packet energy network. First only 10 blocks have been used with different output power level. Then those 10 blocks are used to make 2000 blocks to behave like a practical digital grid system consisting of effectively 2000 sources switching randomly and injecting energy packets. Fig. 4 shows the total output power from different blocks. From the simulation plots it can be said that the designed packet energy system can provide stable output power with the presence of large number of blocks switching or injecting energy packets to the grid randomly.

Large variable load with the presence of random fluctuations is applied in simulation to check the stability of the designed packet energy system. The variable load consists of $1500 \mathrm{~kW}$ constant load, 100 $\mathrm{kW}$ step load and maximum $15 \mathrm{~kW}$ random load fluctuations. Fig. 5 shows the load that has been applied to the system in simulations.

The mean output power from 10 blocks is found $1.38 \times 10^{4} \mathrm{~W}$. As the sum of independent normally distributed random variables is also a normal, the mean of sum of independent variables is the sum of the means of individual variables. Here the mean output power from the 100 blocks is found as $1.44 \times 10^{5}$ $\mathrm{W}$ which is 10 times of the mean output power of 10 blocks. Similarly the mean output power of 1000 blocks and 2000 blocks are $1.44 \times 10^{6} \mathrm{~W}$ and $2.89 \times 10^{6} \mathrm{~W}$. The mean output power of 1000 blocks is 100 times of the mean output power of the 10 blocks. The mean output power of 2000 blocks is double of the mean output power of the 1000 blocks.

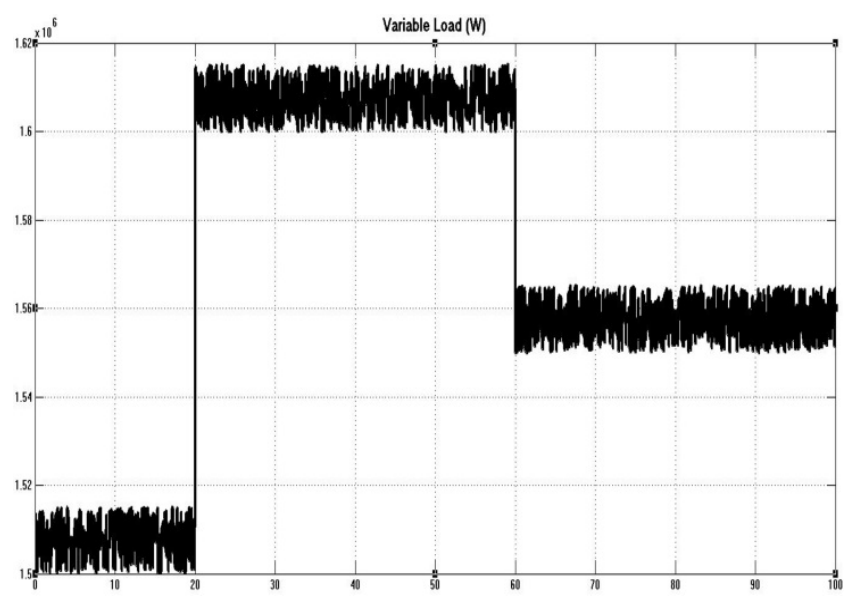

FIG. 5 VARIABLE LOAD USED IN THE SYSTEM

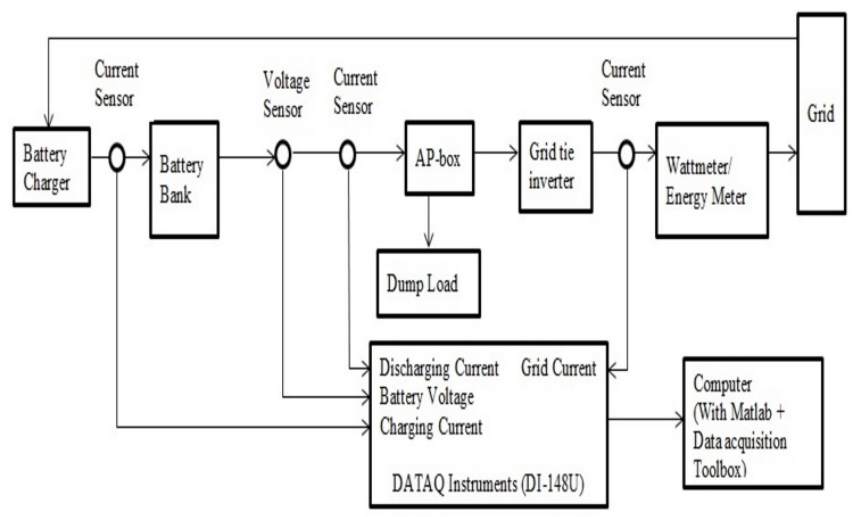

FIG. 6 BLOCK DIAGRAM OF EXPERIMENTAL SETUP 
Comparing the last two plots of fig. 4, it could be concluded that random sources and random load fluctuations still leads to an almost steady output.

\section{Implementation of Battery-Based Storage System}

Fig. 6 shows the block diagram of the designed battery based energy storage system [10]. And fig. 7 shows the experimental setup used in the laboratory for the data collection and analysis [10]. Apparatus used in the experiment are described below:

\section{Battery Specification}

Four 12V 7Ah lead acid batteries have been used in series to get $48 \mathrm{~V}$ DC output. The manufacturer and the model no. are B.B BATTERY and BP7-12 respectively. The maximum charging current is $2.1 \mathrm{~A}$ and maximum allowed discharge current for $5 \mathrm{sec}$ is $105 \mathrm{~A}$.

\section{Grid Tie Inverter UWT-I-250 STARTER KIT}

Grid Tie Inverter UWT-I-250 STARTER KIT consists of AP-box, grid tie inverter and dump load. The description of the components is given below:

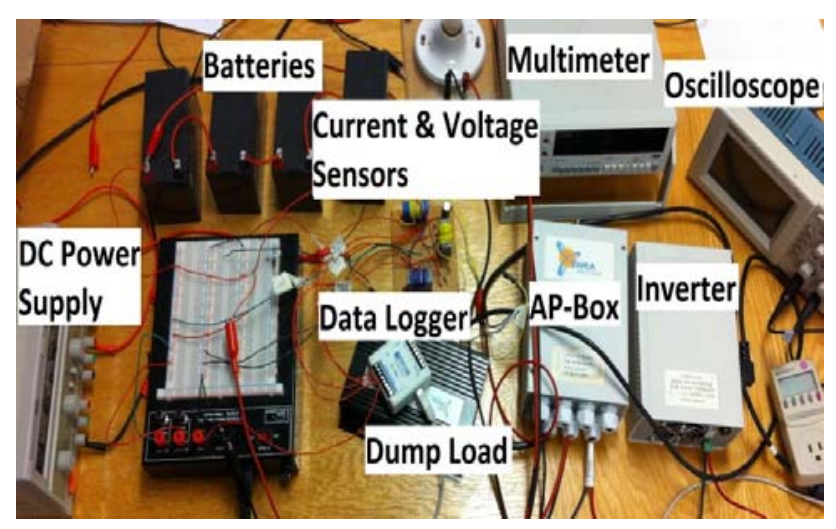

FIG. 7 EXPERIMENTAL SETUP IN LABORATORY

\section{AP-box with 24 V AC/12 V DC Adaptor}

The AP-box is an adaptor box between the batteries and the grid tie inverter UWT-I-250 The AP-box is a connecting and safety box for a typical installation. Total 4 pieces of grid tie inverters UWT-I-250 can be connected (up to 1000 Watt) with one AP-box. It protects electronics and also the batteries together with the internal safety items and together with the Dump load. The energy will be absorbed by the Dump load automatically when the input is above $52 \mathrm{~V} \mathrm{DC}$. It is always connected with a fuse in series with the input supply.

\section{Grid Tie Inverter}

Grid-tie inverter connects the battery storage to the grid. The input of this inverter is $48 \mathrm{~V} \mathrm{DC}$ as 4 batteries have been used in series. Maximum 4 pcs Grid Tie Inverters can be installed with one Starter-Kit. In this case one grid tie inverter has been used.

\section{DUMPLOAD DL-2-100}

DUMPLOAD DL-2-100 has been connected to the APbox. The AP-box will switch on the Dump load automatically when the DC-out of the batteries becomes higher than $52 \mathrm{~V}$. Two resistors of 100 Watt are installed inside the Dump load.

\section{Voltage and Current Sensors}

\section{1) Voltage Sensor}

A voltage divider circuit has been used to measure the voltage of the battery bank.

\section{2) Current Sensors}

Current Transducer LA 55-P has been used to measure the discharging current of the batteries. This is closed loop (compensated) current transducer using the Hall Effect. This sensor has excellent accuracy and low temperature drift. Current Transducer CLN-50 has also been used to measure output current of the inverter which is AC.

Primary and Secondary nominal current (rms) is $50 \mathrm{~A}$ and $50 \mathrm{~mA}$ respectively for both sensors. The conversion ratio is 1:1000. Both sensors are calibrated to get the actual current measurements.

\section{Data Acquisition Using the MATLAB Data Acquisition Toolbox}

MATLAB's Data Acquisition Toolbox (DAT) allows MATLAB to acquire data from sensors and to send out electrical signals that can be used to control or drive external devices. DI-148U has been used to acquire the data from sensors. The 32-bit versions of Data Acquisition Toolbox and MATLAB have been installed on a 32-bit Windows OS. Legacy interface is used for DATAQ data acquisition hardware [11].

3 analog input signals have been defined to measure the battery voltage, discharging current and the grid current from the experimental setup. The sampling time is set to 1s. The mean value of the acquired data from each analog port has been taken as samples per trigger is set to 1000 .

\section{Smart Meter}

In the present analysis a modification has been assumed in a smart meter. The existing smart meter 
can communicate with following communication channels:

- Optical port - IR communication interface

- DLC modem

- GSM/GPRS communication interface with antenna

- RS 485 comm. interface

- M-Bus communication interface

And the existing smart meter can do the following functions using these communication channels [12]

- Collection of energy consumption information

- Reading of energy consumption information on request.

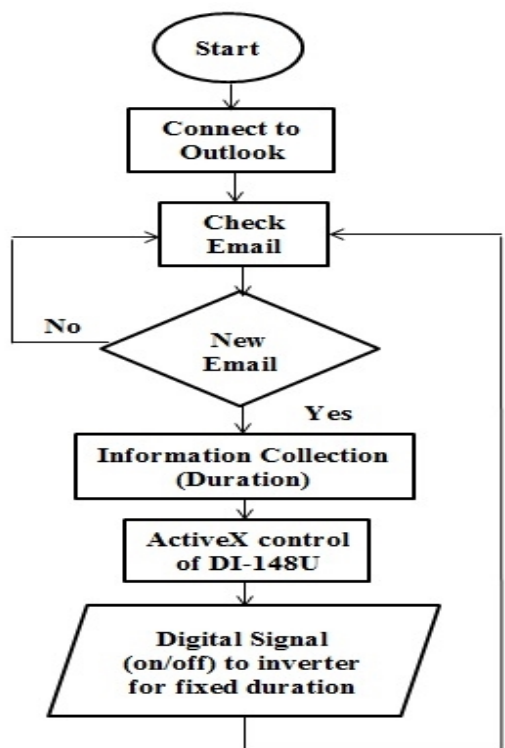

FIG. 8 FLOWCHART TO CONTROL INVERTER ON/OFF USING MATLAB

- Collection of supply quality information (e.g. sags, voltage measurements) of individual customers.

- Collection of information saved in profiles of individual customers and/or a (larger) number of customers.

- Collection of power failure duration information of individual customers and/or a (larger) number of customers.

- Setting and retrieving different tariff structures

- Retrieving device status.

- Remote connection and disconnection of the energy supply of individual customers.

But a small block can be added to the existing smart meter to use it with the battery storage system. The modified smart meter will measure the battery voltage.
Then smart meter can calculate the state of charge of the battery storage from that measured battery voltage using the equation (6) (a simple approximation). A complicated method can be also implemented in the microcontroller of the smart meter to determine the state of charge of the battery.

$$
S O C=\frac{V_{\text {present }}}{V_{\text {full }}} \times 100 \%
$$

In this research it is proposed that smart meter will send the battery storage status information to the smart energy dispatch center. After getting the energy storage status, control center randomly select energy system depending on the energy demand and energy production.

In this experiment it is assumed that energy dispatch center will communicate with the smart meter through GSM network. To implement this idea, it is assumed that control center will send request for energy packet to the smart meter through an email. Fig. 8 shows the algorithm to implement this idea in Matlab. In the email there are two information. One is the request for the inverter to be turned on and another is the duration of the energy packet. Inverter will run at full power during that duration. After getting the request of the energy packet from the dispatch center, the information has been collected by the Matlab. Using the activex control in Matlab for the DI-148U, digital signal (on/off) has been generated for the specified duration determined by the dispatch center. This digital signal (on/off) is provided to the inverter. As the inverter starter kit used in this experiment doesn't allow to disconnect the grid side, the connection and disconnection of the input side of the inverter has been done to produce a power packet. But if inverter allows disconnection of the grid side, a relay can be used which can be controlled with the digital output from the DI-148U. A solid state relay can also be used to control the energization of the winding of the depending on the digital signal from the DI-148U.

\section{Experimental Results}

Fig. 9 shows the battery voltage (V), discharging current (A) and discharging power (W) during discharging the battery to sell energy to the grid. Initially battery voltage was $48.26 \mathrm{~V}$. It reaches $47.3 \mathrm{~V}$ when inverter is on and it reaches back to $47.9 \mathrm{~V}$ when the inverter is off. Batteries have been discharged for 180 seconds (approx.) and the discharging current from battery is 1.2A (approx.). During this test the discharging power is 56W (approx.) for demonstration. 


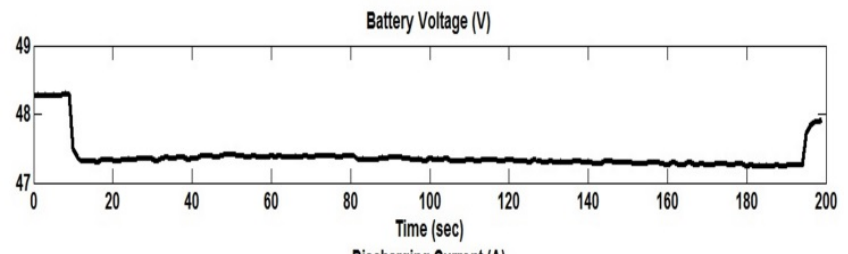

Discharging Current (A)

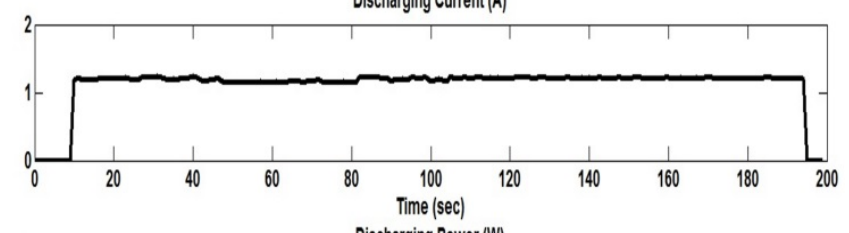

Discharging Power (W)

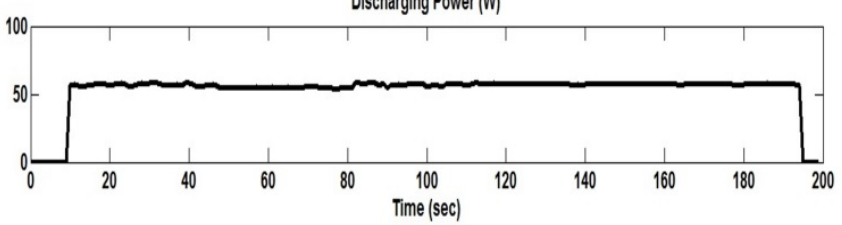

FIG. 9 BATTERY VOLTAGE, DISCHARING CURRENT AND DISCHARGING POWER WITH RESPECT TO TIME
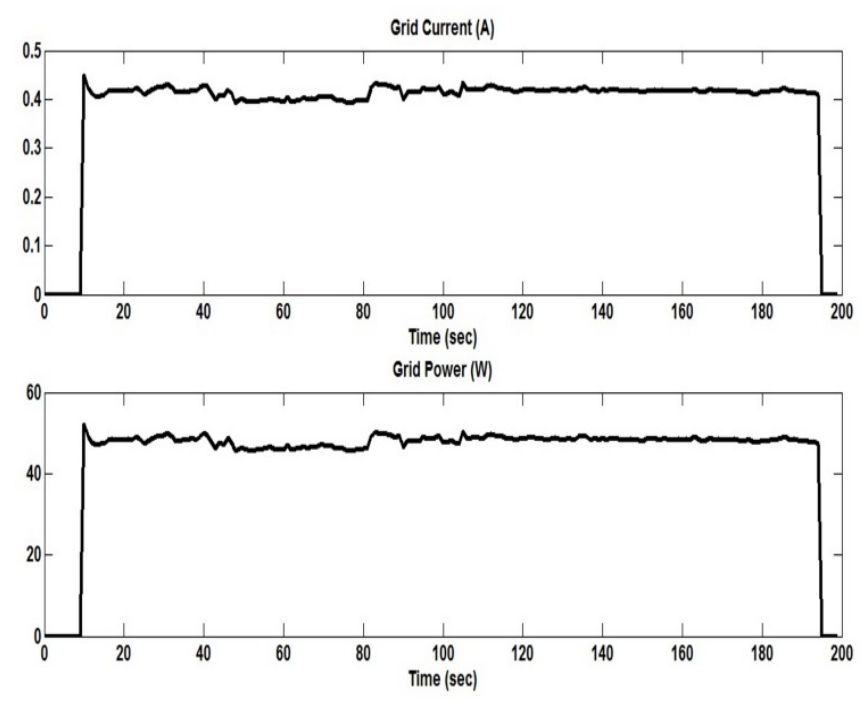

FIG. 10 INVERTER OUTPUT CURRENT AND POWER GOING TO GRID WITH RESPECT TO TIME

Fig. 10 shows the grid current and power sold to the grid. The grid current and the power sold to the grid is found $0.43 \mathrm{~A}$ (approx.) and $49 \mathrm{~W}$ (approx.). So the inverter efficiency is $49 / 56=87.5 \%$.

From the Fig. 10, it can be said that implemented system can supply energy packet of variable duration as determined by the energy dispatch center.

\section{Conclusions}

This paper discusses a wind energy based packet energy system. Grid connected wind energy system with battery storage has been simulated in Matlab/Simulink. The basic system has been converted into transfer function model to design energy packet network. After determining the transfer function model of the wind energy system, a PID controller has been used to get a constant output power from the basic system. A large number of blocks have been considered with different constant output power similar to a practical system. Random switching has been done to get the power in packets from the model. Simulation results indicate that the designed packet energy network system consisting of thousands of smaller packet energy system is able to provide a flexible and stable power. A small prototype has been implemented with battery storage to demonstrate control to produce an energy packet. And experimental results show that it is possible to make such energy packet in the existing system. The proposed packet energy system is based on renewable energy sources with local storage. With the help of energy packet network, a smart energy dispatching centres can take full advantage of renewable energy sources. The proposed packet energy network could be implemented using already available commercial technology.

\section{ACKNOWLEDGEMENT}

Authors would like to thank the Natural Sciences and Engineering Research Council of Canada (NSERC) for funding this research

\section{REFERENCES}

A. Shiki, A. Yokoyama, J. Baba, T. Takano, T. Gouda, and Y. Izui, "Autonomous decentralized control of supply and demand by inverter based distributed generations in isolated microgrid," IEEJ Transactions on Power and Energy, vol. 127, pp. 95-103, 2007.

E. Gelenbe, "Energy packet networks: smart electricity storage to meet surges in demand," in Proceedings of the 5th International ICST Conference on Simulation Tools and Techniques. ICST (Institute for Computer Sciences, Social-Informatics and Telecommunications Engineering), 2012, pp. 1-7.

H. Suzuki, "Advanced metering infrastructure based on smart meters," IEEJ Transactions on Power and Energy, vol. 127, pp. 977-980, 2007.

M. S. Hossain and M. T. Iqbal, “Grid connected energy storage system to profit from net-metering and variable rate electricity," in press Electrical and Computer Engineering (CCECE), 2014 27th Annual IEEE Canadian Conference on, 2014.

P. Rezaei, J. Frolik, and P. Hines, “Packetized plug-in electric 
vehicle charge management," Smart Grid, IEEE Transactions on, vol. 5, pp. 642-650, 2014.

R. Abe, H. Taoka, and D. McQuilkin, “Digital grid: communicative electrical grids of the future," Smart Grid, IEEE Transactions on, vol. 2, no. 2, pp. 399-410, 2011.

T. Jin and M. Mechehoul, "Ordering electricity via internet and its potentials for smart grid systems," Smart Grid, IEEE Transactions on, vol. 1, no. 3, pp. 302-310, 2010.

T. Takuno, M. Koyama, and T. Hikihara, "In-home power distribution systems by circuit switching and power packet dispatching," in Smart Grid Communications (SmartGridComm), 2010 First IEEE International Conference on. IEEE, 2010, pp. 427-430.

X. Fang, S. Misra, G. Xue, and D. Yang, "Smart gridthe new and improved power grid: a survey," Communications
Surveys \& Tutorials, IEEE, vol. 14, no. 4, pp. 944-980, 2012.

Y. Hayashi, S. Kawasaki, J. Matsuki, S. Wakao, J. Baba, M. Hojo, A. Yokoyama, N. Kobayashi, T. Hirai, and K. Oishi, "Active coordinated operation of distribution network system for many connections of distributed generators," IEEJ Transactions on Power and Energy, vol. 127, pp. 4151, 2007.

“Matlab." [Online]. Available: https://www.mathworks.com/products/daq/supported/d ataqinstruments.html

[Online]. Available: http://www.iskraemeco.co.uk/index_files/Mx37y_Techni cal_Description_ENG_v2.00.pdf 